\title{
WHAT CAN SOUND SYMBOLISM TELL US ABOUT THE EVOLUTION OF LANGUAGE? A COMPARATIVE STUDY IN HUMANS AND GREAT APES
}

\author{
KONSTANTINA MARGIOTOUDI ${ }^{* 1,2}$, MANUEL BOHN ${ }^{4}$, MATTHIAS \\ ALLRITZ $^{5}$ and FRIEDEMANN PULVERMÜLLER ${ }^{1,2,3}$ \\ *Corresponding Author: konstantina.margiotoudi@fu-berlin.de \\ ${ }^{1}$ Brain Language Laboratory, Department of Philosophy and Humanities, Frei \\ Universität,Berlin,Germany \\ ${ }^{2}$ Berlin School of Mind and Brain, Humboldt Universität, Berlin, Germany \\ ${ }^{3}$ Einstein Center for Neurosciences,Berlin, Germany \\ ${ }^{4}$ Leipziger Foschungszentrum für frühkindliche Entwicklung, Universität Leipzig, \\ Germany \\ ${ }^{5}$ School of Psychology \& Neuroscience, University of St Andrews, St Andrews, \\ Scotland
}

There has been a long debate in the literature of semantics between the arbitrariness of language proposed by Saussure (1959) and the non-arbitrary associations, known as sound symbolism. Sound symbolism is a form of iconicity based on similarity between a linguistic form and the sensory-motor properties of its referent (Perniss \& Vigliocco, 2014). A classic example of sound symbolism is the sound-shape correspondence, as described by Köhler (1929), where the non-word "maluma" was judged to be a good match with a round shape whereas the non-word "takete" matched better to a spiky shape.

Recent theories have highlighted the relevant role of sound symbolism and that of iconicity for the evolution of language (Ramachandran \& Hubbard, 2001; Arbib, 2005; Imai \& Kita, 2014; Perniss \& Vigliocco 2014).

In other words, iconic signals are proposed as the starting point for the evolution of language. Sound symbolic mimicking of the external word with the movement of lips and tongue is another form of iconicity that would fit these theories.

Moreover linked to theories on embodied cognition (Barsalou et al., 2003), language processing is proposed to be based on distributed neural circuits grounded in the action and perception system of the brain and mind (Pulvermüller, 2018). Sound symbolism has been proposed as the linkage between language and human sensory-motor experience, playing a determinant role on the evolution of language (Perniss \& Vigliocco, 2014).

Despite this theoretical interest on the phylogenetic origins of sound 
symbolism, as far as we are concerned there have been no comparative studies in testing sound symbolic associations in humans and great apes. In addition, considering the new evidence on the perception of iconic gestures in chimpanzees (Bohn et al., 2016), the present study aims to explore whether our closest living relatives are able of perceiving vocal iconic mappings between shapes and sounds.

For that purpose, we ran a two-alternative forced choice (2AFC) audiovisual task, the classic "maluma"-"takete" paradigm (Köhler, 1929). 24 healthy human subjects, four chimpanzees (Pan troglodytes) and two gorillas (Gorilla gorilla gorilla) took part in the study. During the task the subjects listened to a word copresented with two shapes, one edgy and one round, and they had to choose one of the two co-presented shapes. In order to avoid any habituation effect, we generated disyllabic non-words that sounded more "round" or "edgy" based on combination of vowels and consonants that sound more "round" or "edgy" in accordance with the literature (Nielsen \& Rendall, 2013; McCormick et al., 2015).

We also generated shapes that looked edgy or round. Both sounds and shapes were rated with an online questionnaire in order to select those that have the higher degree of "edginess" or "roundness". The human subjects were tested in a behavioral booth by responding with a button box and choosing one of the two shapes that matched the aurally simultaneously presented non-word.

In accordance with previous studies, humans preferred to associate round shapes to words that consisted of round vowels, voiced plosives and sonorants. In contrast, disyllabic words that consisted of edgy vowels and voiceless plosives or fricatives were associated more with edgy shapes.

Based on the findings from humans we are currently conducting an analogous study in great apes at the Wolfgang Kohler Primate Research Center, Zoo Leipzig, Germany. Specifically six chimpanzees (Pan troglodytes, 3 males) and two gorillas (Gorilla gorilla gorilla, 2 females) that were touch screen trained, are tested with the same stimuli in a comparable task. We modified the initial task by increasing the number of trials, in order to have data comparable to the human ones, and by rewarding with food $50 \%$ of the trials in order to keep them engaged to the task.

Based on the results of this study, we will shed light to different hypothesis regarding the role of iconicity and that of sound symbolism in the phylogenetic origins of language. Moreover, new questions will raise regarding the mechanisms that boost the evolution of language. Perhaps the different characteristics of the articulatory system (Fitch, 2000) or differences in the 
brain's neuroanatomical structure for spoken language and verbal working memory between human and non human primates (Schomers \& Pulvermüller, 2016) may have limited the role of verbal iconic communication in the evolution of language, so that apes would not show evidence of sound symbolic processing.

\section{References}

Arbib, M. A. (2005). From monkey-like action recognition to human language An evolutionary framework for neurolinguistics. Behavioral and brain sciences, 28(2), 105-124.

Barsalou, L. W., Simmons, W. K., Barbey, A. K., \& Wilson, C. D. (2003). Grounding conceptual knowledge in modality-specific systems. Trends in cognitive sciences, 7(2), 84-91.

Bohn, M., Call, J., \& Tomasello, M. (2016). Comprehension of iconic gestures by chimpanzees and human children. Journal of experimental child psychology, 142, 1-17.

Fitch, W. T. (2000). The evolution of speech: A comparative review. Trends in Cognitive Sciences, 4(7), 258-267.

Imai, M., \& Kita, S. (2014). The sound symbolism bootstrapping hypothesis for language acquisition and language evolution. Phil. Trans. R. Soc. B, 369(1651), 20130298.

Köhler, W. (1929). Gestalt psychology. New York, USA: Liveright

McCormick, K., Kim, J., List, S., \& Nygaard, L. C. (2015). Sound to Meaning Mappings in the Bouba-Kiki Effect. In $\mathrm{CogS} c i$.

Nielsen, A. K., \& Rendall, D. (2013). Parsing the role of consonants versus vowels in the classic Takete-Maluma phenomenon. Canadian Journal of Experimental Psychology/Revue canadienne de psychologie expérimentale, 67(2), 153.

Perniss, P., \& Vigliocco, G. (2014). The bridge of iconicity: from a world of experience to the experience of language. Phil. Trans. R. Soc. B, 369(1651), 20130300.

Pulvermüller, F. (2017). Neural Reuse Of Action Perception Circuits For Language, Concepts And Communication. Progress in Neurobiology.

Ramachandran, V. S., \& Hubbard, E. M. (2001). Synaesthesia--a window into perception, thought and language. Journal of consciousness studies, 8(12), 334.

Saussure, F. D. (1959). Course in General Linguistics. Ed. Charles Bally, Albert Sechehaye, and Albert Riedlinger. Trans. Wade Baskin. New York: Philosophical Library.

Schomers, M. R., \& Pulvermüller, F. (2016). Is the sensorimotor cortex relevant for speech perception and understanding? An integrative review. Frontiers in human neuroscience, 10. 